\title{
PULMONARY HYPERTENSION AFTER OPERATIONS FOR CONGENITAL HEART DISEASE: ANALYSIS OF RISK FACTORS AND MANAGEMENT
}

Ko Bando, MD

Mark W. Turrentine, MD

Thomas G. Sharp, MD

Yasuo Sekine, MD

Thomas X. Aufiero, MD

Kyung Sun, MD

Eri Sekine, BS, MPH

John W. Brown, MD
Background: Management of pulmonary hypertension, a potentially fatal complication of operations to correct congenital heart disease, has evolved through the last 15 years. Monitoring of pulmonary arterial pressure and mixed venous saturation became available, and prophylactic use of $\alpha$-blockers and other vasodilators increased. This study examines risk factors for morbidity and mortality from pulmonary hypertension after operations to correct congenital heart disease and evaluates the impact of management changes on outcomes. Methods: By means of multivariable logistic regression analysis, 880 high-risk patients with congenital heart disease (of 2484 patients undergoing cardiopulmonary bypass between January 1980 and December 1994) were analyzed to determine which were at risk for postoperative pulmonary hypertension and its associated morbidity and mortality. Results: Patients with atrioventricular canal $(n=182)$, truncus arteriosus $(n=47)$, total anomalous pulmonary venous connection $(n=$ 90), transposition of great arteries $(n=97)$, hypoplastic left heart syndrome $(n=50)$, and ventricular septal defect $(n=414)$ demonstrated a higher risk of postoperative pulmonary hypertension. By multivariable logistic regression, preoperative pulmonary hypertension $(p<0.0001$, absence of mixed venous saturation monitoring $(p<0.0001)$, and absence of prophylactic $\alpha$-blockade $(p=0.0004$ ) significantly increased postoperative pulmonary hypertension. Preoperative pulmonary hypertension $(p<$ $0.001)$ and absence of prophylactic $\alpha$-blockers $(p=0.0004)$ were significant risk factors for in-hospital death related to pulmonary hypertension. Repair at older age (except in the case of total anomalous pulmonary venous connection) was a significant risk for postoperative pulmonary hypertension $(p=0.03$ ). Conclusion: Mixed venous saturation monitoring and $\alpha$-receptor blockade reduced the incidence of pulmonary hypertension after operations for congenital heart disease. Early definitive repair reduced morbidity and mortality from postoperative pulmonary hypertension. (J Thorac Cardiovasc Surg 1996;112:1600-9)
From the Section of Cardiothoracic Surgery, James W. Riley Hospital for Children and Indiana University Medical Center, Indianapolis, Ind.

Read at the Seventy-sixth Annual Meeting of The American Association for Thoracic Surgery, San Diego, Calif., April 28-May 1, 1996.

Received for publication May 6, 1996; revisions requested June 26, 1996; revisions received July 29, 1996; accepted for publication July 31, 1996.

Address for reprints: Ko Bando, MD, Section of Cardiothoracic Surgery, Indiana University Medical Center, 545 Barnhill Dr., EM 215, Indianapolis, IN 46202-5123.

Copyright $(\mathcal{C} 1996$ by Mosby-Year Book, Inc.

$0022-5223 / 96 \$ 5.00+0 \quad \mathbf{1 2 / 6 / 7 7 1 4 2}$
Q eports of surgical management of complex conRenital heart disease during the past 15 years indicate a general trend of steady decline in perioperative mortality. However, pulmonary hypertension as a result of increased pulmonary vascular resistance remains one of the most important determinants of perioperative morbidity and mortality, as well as longterm survival after cardiac operations. ${ }^{1-6}$ This potentially fatal complication occurs most commonly, but not exclusively, among neonates and infants who are intubated after operation for the repair of a congenital cardiac defect. Few studies, however, have analyzed incidence of and risk factors for development of postoperative pulmonary hypertension among various forms of complex congenital heart disease. 
Monitoring and management of postoperative pulmonary hypertension have been evolving in our institution since the middle 1980s. Major changes include monitoring of pulmonary arterial pressures and mixed venous saturation ( $\mathrm{S}_{\overline{\mathrm{V}}}{ }_{2}$ ) and prophylaxis with $\alpha$-blockers (chlorpromazine and prazosin) and other vasodilators (nitroglycerin and sodium nitroprusside). The purpose of this study was to determine which patients were at high risk for postoperative pulmonary hypertensive events and to analyze risk factors for morbidity and mortality from postoperative pulmonary hypertension.

\section{Patients and method}

Patients. Two thousand four hundred eighty-four patients with congenital heart disease were operated on with cardiopulmonary bypass between January 1980 and December 1994 at James W. Riley Hospital for Children at Indiana University Medical Center. High-risk groups were defined as those in which the incidence of postoperative pulmonary hypertensive events was at least $5 \%$ of total cases or those with a hospital mortality rate of at least $5 \%$ among patients in whom postoperative pulmonary hypertension developed. Patients with rare congenital heart diseases (fewer than 10 cases in this 15-year experience) were excluded from this analysis to lessen the chance of a type II statistical error. Children who received palliation at other institutions before being referred to our center were also excluded. Patients with other associated cardiovascular and noncardiovascular lesions were included.

Preoperative evaluation. Preoperative diagnostic techniques have evolved during the last 15 years. Cardiac catheterization was performed for most patients treated before 1989. Echocardiography has been performed routinely since 1978 . In most patients with hypoplastic left heart syndrome or transposition of the great arteries, diagnosis was made by echocardiography. Since 1990, atrioventricular canal $(n=14)$ and total anomalous pulmonary venous connection $(n=13)$ have been diagnosed by echocardiography alone.

Preoperative pulmonary hypertension was defined as a systolic pulmonary arterial pressure greater than $50 \%$ of systemic pressure. Prematurity was defined as birth at less than 36 weeks of gestational age or birth weight lower than $2500 \mathrm{gm}$.

Operative management. Our operative management has evolved during the last 15 years. A median sternotomy is performed, any adhesions present are freed, and the external cardiac anatomy is assessed. Cannulation is accomplished by using the ascending aorta for aortic inflow and separate caval cannulas inserted through the right atrial appendage, superior vena cava, or both. Cardiopulmonary bypass is instituted at a flow rate of 2.4 $\mathrm{L} \cdot \mathrm{min}^{-1} \cdot \mathrm{m}^{-2}$, and the perfusate is cooled to $20^{\circ}$ to $28^{\circ} \mathrm{C}$ in most cases. For patients that require circulatory arrest, a single venous cannula is used and the repair is performed after the perfusate is cooled to $15^{\circ} \mathrm{C}$ and maintained for 15 minutes. The left side of the heart is vented with a catheter inserted through the apex of the left ventricle or through the left atrial appendage. Cold crystalloid cardioplegic solution is injected at a total volume of $15 \mathrm{ml} / \mathrm{kg}$. Topical hypothermia is added. The infusion of cardioplegic solution is repeated at 20- to 25 -minute intervals, sooner if electrical activity is noted.

Intraoperative postrepair evaluation and monitoring. As patients are being warmed and weaned from bypass, left atrial, pulmonary arterial, and right atrial oximetric monitoring catheters are inserted for intraoperative and postoperative monitoring for those patients at high risk for postoperative pulmonary hypertension. For the patients without preoperative pulmonary hypertension, a right atrial oximetric catheter alone is used for monitoring $\mathrm{S}_{\mathrm{O}} \mathrm{O}_{2}$.

Intravenous nitroglycerin at a dose of 0.5 to 10 $\mu \mathrm{g} \cdot \mathrm{kg}^{-1} \mathrm{~min}^{-1}$ and nitroprusside at a dose of 0.5 to 4 $\mu \mathrm{g} \cdot \mathrm{kg}^{-1} \mathrm{~min}^{-1}$ are currently the most common medications given in the early postoperative period to patients at high risk. These agents are administered through a right atrial or pulmonary arterial line in an attempt to keep the pulmonary artery pressure at less than $40 \%$ of systemic pressure. If dopamine or epinephrine is required at a dosage of more than $5 \mu \mathrm{g} \cdot \mathrm{kg}^{-1} \mathrm{~min}^{-1}$, it is delivered through the left atrial line in an attempt to reduce the potential pulmonary vasoconstrictive effects.

Prevention strategy for postoperative pulmonary hypertension. Postoperative pulmonary hypertensive events include pulmonary hypertensive crisis and persistent pulmonary hypertension. Pulmonary hypertensive crisis is defined as a syndrome of hyperacute rise of systolic pulmonary pressure ( $>50 \%$ of systemic pressure) accompanied by a profound reduction in cardiac output and a fall in $\mathrm{S}_{\overline{\mathrm{v}}}$. Persistent pulmonary hypertension is defined as postoperative systolic pulmonary arterial pressure more than $50 \%$ of systemic pressure continuing for longer than 6 hours after repair. Patients in the high-risk diagnostic categories for postoperative pulmonary hypertensive events are paralyzed and mechanically ventilated for at least 24 hours. Moderate hyperventilation is used if systolic pulmonary arterial pressure is more than $40 \%$ of systemic pressure. This approach to ventilator management and sedation has been used consistently throughout the 15 years covered by this report.

Intravenous administration of chlorpromazine is begun in the immediate postoperative period at a dose of 0.25 $\mathrm{mg}$, adjusting it for its pulmonary vasodilatory ( $\alpha$-adrenergic blockade) and central nervous system sedative effects as needed to a maximum of $2 \mathrm{mg}$ every 4 hours. If pulmonary hypertension ( $>50 \%$ of systemic pressure) persists after administration of chlorpromazine, prazosin (another $\alpha$-blocker) is given orally or by nasogastric tube beginning with $0.25 \mathrm{mg}$ and adjusting up to $2 \mathrm{mg}$ every 4 hours. If a patient requires chlorpromazine or prazosin, then one or both are continued for 2 to 4 weeks orally after discharge, and the dose is gradually reduced. This $\alpha$-blocker treatment regimen for preventing postoperative pulmonary hypertension was started in late 1989 and has been routinely used since September 1991.

Postoperative evaluation. A complete set of postoperative physiologic data was available for 796 patients (90\%) including arterial blood gas (oxygen tension, carbon dioxide tension, and $\mathrm{pH}$ ), inotropic requirement, rhythm, 
Table I. Incidence of postoperative pulmonary hypertensive events and hospital mortality in high-risk patient groups

\begin{tabular}{lccccc}
\hline \multirow{2}{*}{ Diagnosis } & $\begin{array}{c}\text { Total No. of } \\
\text { patients }\end{array}$ & No. & $\%$ & $\begin{array}{c}\text { No. of early } \\
\text { deaths }\end{array}$ & Mortality (\%) \\
\hline TAPVC & 90 & 36 & 40 & 10 & 11 \\
Truncus arteriosus & 47 & 14 & 30 & 11 & 23 \\
TGA & 97 & 14 & 14 & 6 & 6 \\
VSD & 414 & 59 & 14 & 10 & 2 \\
HLHS & 50 & 4 & 8 & 24 & 48 \\
AV canal & 182 & 11 & 6 & 14 & 8 \\
Total & 880 & 138 & 16 & 75 & 8.5 \\
\hline
\end{tabular}

PHE, Pulmonary hypertensive events; TAPVC, total anomalous pulmonary venous connection; TGA, transposition of the great arteries; VSD, ventricular septal defect; $H L H S$, hypoplastic left heart syndrome; $A V$, atrioventricular.

pacemaker requirement, systemic arterial and pulmonary arterial pressures, atrial pressures (right, left, or both), and right atrial and pulmonary arterial oxygen saturations. Evidence of significant postoperative left and or right ventricular dysfunction was evaluated carefully by transesophageal echocardiography. In-hospital (perioperative) death was defined as death occurring within 30 days of the operation or before discharge from the hospital after repair. Postoperative patient status 30 days after operation was determined by direct evaluation of the patient by the pediatric cardiologist and surgeon or by letters from referring physicians. One month follow-up data were available for 844 patients $(96 \%)$.

Statistical analysis. Data were analyzed with the SAS software package (Statistical Analysis Systems, Cary, N.C.). Initially, patients at high risk for the development of pulmonary hypertensive events were determined according to the previously described definition. Trends in postoperative patient management in three time frames (1980 to 1984, 1985 to 1989,1990 to 1994) were compared by Mantel-Haenszel $\chi^{2}$ analysis.

A multivariable logistic regression model was used to identify independent risk factors for development of pulmonary hypertensive events and mortality related to pulmonary hypertensive events in the cohort of 880 highrisk patients. Variables entered into risk factor analysis are summarized in Appendix. Selection of independent variables was a forward stepwise method with a critical $p$ value for variable inclusion and exclusion of 0.15 . The $C$ statistic was used to determine model fit. ${ }^{7}$ Calibration was determined by van Houwelingen and le Cessie's heuristic shrinkage estimate. ${ }^{8}$ A $p$ value lower than 0.05 was considered significant.

\section{Results}

Incidence of postoperative pulmonary hypertensive events. Among 2484 patients with congenital heart disease operated on with the use of cardiopulmonary bypass, those with atrioventricular canal, truncus arteriosus, total anomalous pulmonary venous connection, transposition of the great arteries, hypoplastic left heart syndrome, and ventricular septal defect were determined to be at high risk for the development of postoperative pulmonary hypertensive events (Table I). All of these high-risk groups had an incidence of pulmonary hypertensive events higher than $5 \%$. In contrast, pulmonary hypertensive events developed in fewer than $1.5 \%$ of patients after definitive repair of the other low-risk lesions (data not shown). Although patients with left ventricular outflow obstruction, coarctation of aorta, mitral and aortic regurgitation, or anomalous origin of left coronary artery may have increased pulmonary vascular resistance, cases of closed operation and rare cases (fewer than 10 cases in this series) were excluded.

Perioperative mortality and mortality related to pulmonary hypertensive events. Seventy-five children $(8.5 \%)$ in these six high-risk congenital heart disease groups died during the perioperative period (Table I). The mortality rates among those patients within each diagnostic group in whom pulmonary hypertensive events developed are depicted in Table II. Overall, $23 \%$ of patients in whom pulmonary hypertensive events developed during the last 15 years of our experience died.

Trends in postoperative management. Trends in the evolution of postoperative management are summarized in Table III. Routine monitoring of $\mathrm{Sv}_{\mathrm{V}}{ }_{2}$ was initiated in September 1986; monitoring of postoperative pulmonary arterial pressure began in June 1984. Since August 1990, intraoperative transesophageal echocardiography has been used routinely to assess the completeness of the repair of complex congenital heart disease.

Trends in incidence of and mortality rates associated with pulmonary hypertensive events. The incidence of pulmonary hypertensive events declined significantly, from $30.5 \%$ (1980 to 1984) to $6.8 \%$ (1990 to 1994). Although the overall early 
mortality rate did not change, the early mortality rate associated with pulmonary hypertensive events declined substantially, from $5.7 \%$ (1980 to 1984) to $2.4 \%$ (1990 to 1994). Moreover, pulmonary hypertension was the primary cause of early death $(71 \%$, 10/14 patients at risk) in 1980 to 1984 , but this rate had declined significantly to $29 \%$ (11/38 patients at risk) in 1990 to 1994.

Risk factors for development of pulmonary hypertensive events. Factors associated with development of postoperative pulmonary hypertensive events were analyzed by univariate and logistic regression analyses. By univariate analysis, absence of $\mathrm{Sv}_{2}$ monitoring $(p<0.0001)$, absence of prophylaxis with $\alpha$-blockers $(p<0.0001)$, preoperative pulmonary hypertension $(p<0.0001)$, and prematurity $(p=0.02)$ were significant risk factors. By multivariable logistic regression, preoperative pulmonary hypertension, absence of $\mathrm{S}_{\overline{\mathrm{v}}} \mathrm{O}_{2}$ monitoring, and absence of prophylaxis with $\alpha$-blockers were independent risk factors for the development of postoperative pulmonary hypertensive events (Table IV).

Risk factors for early death associated with pulmonary hypertensive events. By univariate analysis, year of operation $(p=0.06)$, aortic crossclamp time $(p=0.02)$, monitoring of pulmonary arterial pressure $(p=0.06)$, preoperative pulmonary hypertension $(p=0.01)$, and prophylaxis with $\alpha$-blockers $(p=0.007)$ were identified as risk factors for in-hospital death associated with pulmonary hypertensive events. With a multivariable logistic regression model, preoperative pulmonary hypertension, absence of prophylactic $\alpha$-blockade, and monitoring of pulmonary arterial pressure were identified as independent risk factors for in-hospital death associated with pulmonary hypertensive events (Table $\mathrm{V})$.

Impact of timing of definitive repair on development of pulmonary hypertensive events. Because early definitive repair, before the development of significant histologic changes in the pulmonary arteries, may reduce the incidence of postoperative pulmonary hypertension, each high-risk diagnostic category was subdivided according to the patient's age at repair for comparison of incidences of postoperative pulmonary hypertensive events (Table VI). Except in the total anomalous pulmonary venous connection group, the incidence of pulmonary hypertension was higher among patients who underwent repair at an older age. To determine whether timing of the repair might have impacted the devel-
Table II. Hospital mortality associated with pulmonary hypertensive events

\begin{tabular}{lcrr}
\hline & $\begin{array}{c}\text { Early deaths } \\
\text { associated with } \\
\text { Diagnosis }\end{array}$ & \multicolumn{2}{c}{ PHE } \\
\cline { 3 - 4 } \cline { 3 - 4 } PHE & No. & $\%$ \\
\hline AV canal & 4 & 4 & 100.0 \\
Truncus arteriosus & 6 & 11 & 54.5 \\
TGA & 7 & 14 & 50.0 \\
TAPVC & 3 & 14 & 21.4 \\
VSD & 6 & 36 & 16.7 \\
Total & 5 & 59 & 8.5 \\
\hline
\end{tabular}

PHE, Pulmonary hypertensive events; HLHS, hypoplastic left heart syndrome; $A V$, atrioventricular; $T G A$, transposition of the great arteries; $T A P V C$, total anomalous pulmonary venous connection; $V S D$, ventricular septal defect.

opment of postoperative pulmonary hypertensive events, patients with total anomalous pulmonary venous connection were excluded. Risk factors for the development of pulmonary hypertensive events were then reanalyzed. By multivariable logistic regression, definitive repair at older age, absence of $\mathrm{S}_{\mathrm{v}} \mathrm{O}_{2}$ monitoring, and preoperative pulmonary hypertension were all significant risk factors for the development of pulmonary hypertension (Table VII).

\section{Discussion}

Reactive or persistent pulmonary hypertension has been one of the most significant causes of morbidity and mortality after operation for congenital heart disease. Only a few studies have attempted to elucidate the risk factors, pathophysiology, and management of postoperative pulmonary hypertension. ${ }^{9}, 10$ It has been difficult to determine which patients with which specific congenital cardiac lesions will have postoperative pulmonary vascular disease. ${ }^{11}$ This study was performed to determine the incidence of and risk factors for the development of this complication in different categories of congenital heart defects and to analyze the impact on outcome of changes in monitoring and management.

This study confirms several important clinical impressions that those of us involved in congenital heart surgery have "known" for a long time. First, preoperative pulmonary hypertension is the most significant risk factor for the development of postoperative pulmonary hypertensive events and deaths related to this complication (Tables IV and V). Second, patients with atrioventricular canal, truncus arteriosus, transposition of the great arteries, ven- 
Table III. Trends in postoperative management, incidence of pulmonary hypertensive events, and mortality of patients at high risk between 1980 and 1994

\begin{tabular}{|c|c|c|c|c|c|c|c|}
\hline & \multicolumn{2}{|c|}{$\begin{array}{c}1980-1984 \\
(n=177)\end{array}$} & \multicolumn{2}{|c|}{$\begin{array}{l}1985-1989 \\
(n=246)\end{array}$} & \multicolumn{2}{|c|}{$\begin{array}{l}1990-1994 \\
(n=457)\end{array}$} & \multirow[b]{2}{*}{$p$} \\
\hline & No. & $\%$ & No. & $\%$ & No. & $\%$ & \\
\hline $\mathrm{Sv}_{2}$ monitoring & 1 & 0.6 & 186 & 75.6 & 457 & 100.0 & $<0.001$ \\
\hline PAP monitoring & 12 & 6.8 & 115 & 46.8 & 327 & 71.6 & $<0.001$ \\
\hline NTG/nitroprusside treatment & 18 & 10.2 & 36 & 14.6 & 156 & 34.1 & $<0.001$ \\
\hline CP/PR prophylaxis & 0 & 0.0 & 5 & 2.0 & 263 & 57.5 & $<0.001$ \\
\hline Incidence of PHE & 54 & 30.5 & 53 & 21.5 & 31 & 6.8 & $<0.001$ \\
\hline Early mortality associated with $\mathrm{PHE}$ & 10 & 5.7 & 14 & 5.7 & 11 & 2.4 & 0.076 \\
\hline Early mortality & 14 & 7.9 & 23 & 9.4 & 38 & 8.3 & 0.861 \\
\hline
\end{tabular}

$P A P$, Pulmonary arterial pressure; $N T G$, nitroglycerin; $P H E$, pulmonary hypertensive events.

Table IV. Risk factors for development of pulmonary hypertensive events according to multivariable logistic regression

\begin{tabular}{lrrrr}
\hline & & & \multicolumn{2}{c}{ Wald confidence limits } \\
\cline { 3 - 5 } Factors & \multicolumn{1}{c}{$p$} & Odds ratio & Lower & Upper \\
\hline Preoperative PH & $<0.0001$ & 11.53 & 7.32 & 18.15 \\
CP/PR prophylaxis & 0.0004 & 0.36 & 0.20 & 0.63 \\
$\mathrm{~S}_{\mathrm{v} \mathrm{O}_{2}}$ monitoring & $<0.0001$ & 0.35 & 0.22 & 0.57 \\
\hline
\end{tabular}

$C$ statistics $0.81 ; \chi^{2}$ for covariates 173.67 with 3 degrees of freedom $(p=0.0001)$. $P H$, Pulmonary hypertension; $C P$, chlorpromazine; $P R$, prazosin.

Table V. Risk factors for early death associated with pulmonary hypertensive events according to multivariable logistic regression

\begin{tabular}{lcccc}
\hline \multicolumn{1}{c}{ Factors } & & & \multicolumn{2}{c}{ Wald confidence limits } \\
\cline { 3 - 5 } & $p$ & Odds ratio & Lower & Upper \\
\hline PAP monitoring & 0.03 & 2.51 & 1.10 & 5.75 \\
Preoperative PH & 0.036 & 2.20 & 1.05 & 4.59 \\
ACC time & 0.055 & 1.01 & 1.00 & 1.02 \\
CP/PR prophylaxis & 0.009 & 0.26 & 0.09 & 0.71 \\
\hline
\end{tabular}

$C$ statistics $0.74 ; \chi^{2}$ for covariates 23.94 with 4 degrees of freedom $(p=0.0001) . P A P$, Pulmonary arterial pressure; $P H$, pulmonary hypertension; $A C C$, aortic crossclamp; $C P$, chlorpromazine; $P R$, prazosin.

tricular septal defect, hypoplastic left heart syndrome, and total anomalous pulmonary venous connection are at high risk for the subsequent development of pulmonary hypertensive events.

Hypoxemia, hypercapnia, metabolic acidosis, restlessness, and tracheal suctioning may increase pulmonary vasoreactivity and thus trigger postoperative pulmonary hypertensive events. ${ }^{12}$ Moderate hyperventilation with a high fraction of inspired oxygen and sedation and paralysis during the first 24 to 48 hours after operation have been basic strategies in our management of these cases during the last 15 years of our experience. Even when all these precipitating factors could be avoided, pulmonary hypertensive events still occurred in some patients. It has been our clinical experience that pulmonary arterial pressures and central venous pressure gradually increase and $\mathrm{S}_{\mathrm{v}} \mathrm{O}_{2}$ decreases before severe pulmonary hypertensive crises occur. Both the severity of pulmonary hypertension and right ventricular failure in patients with persistent pulmonary hypertension were accurately monitored by these indexes. ${ }^{13}$ We therefore initiated routine monitoring of $\mathrm{Sv}_{2}$ and pulmonary arterial pressures in the middle to late 1980s in an attempt to detect the earliest stages of a pulmonary hypertensive crisis and to avoid irreversible changes from persistent pulmonary hypertension (Table III).

Preventive strategies have also evolved during the last 15 years. Prophylactic administration of $\alpha$-blockers and nitroglycerin or nitroprusside has been routinely used during the last 5 years for patients at high risk. Along with improved monitoring and preventive techniques, the incidence of 
Table VI. Impact of timing of definitive repair on postoperative pulmonary hypertensive events

\begin{tabular}{|c|c|c|c|c|c|c|}
\hline \multirow[b]{3}{*}{ Diagnosis } & \multirow{2}{*}{\multicolumn{2}{|c|}{ Timing of definitive repair }} & \multicolumn{4}{|c|}{ Prevalence of PHE } \\
\hline & & & \multicolumn{2}{|c|}{ Early repair } & \multicolumn{2}{|c|}{ Late repair } \\
\hline & Early & Late & No. & $\%$ & No. & $\%$ \\
\hline HLHS & $\leq 30$ days & $>30$ days & $1 / 45$ & 2.2 & $3 / 5$ & 60.0 \\
\hline Truncus arteriosus & $\leq 30$ days & $>30$ days & $2 / 14$ & 14.3 & $12 / 33$ & 36.4 \\
\hline TAPVC & $\leq 30$ days & $>30$ days & $24 / 48$ & 50.0 & $12 / 42$ & 28.6 \\
\hline TGA & $\leq 2 \mathrm{wk}$ & $>2 w k$ & $2 / 30$ & 6.7 & $12 / 67$ & 17.9 \\
\hline VSD & $\leq 6 \mathrm{mo}$ & $>6 \mathrm{mo}$ & $4 / 45$ & 8.9 & $55 / 369$ & 14.9 \\
\hline AV canal & $\leq 6 \mathrm{mo}$ & $>6 \mathrm{mo}$ & $2 / 41$ & 4.9 & $9 / 141$ & 6.4 \\
\hline
\end{tabular}

PHE, Pulmonary hypertensive events; $H L H S$, hypoplastic left heart syndrome; TAPVC, total anomalous pulmonary venous connection; TGA, transposition of the great arteries; $V S D$, ventricular septal defect; $A V$, atrioventricular.

Table VII. Risk factors for development of pulmonary hypertensive events according to multivariable logistic regression, with patients with total anomalous pulmonary venous connection excluded

\begin{tabular}{lcccc}
\multicolumn{1}{c}{} & & \multicolumn{2}{c}{ Wald confidence limits } \\
Factors & $p$ & Odds ratio & Lower & Upper \\
\hline Preoperative $\mathrm{PH}$ & $<0.0001$ & 9.13 & 5.65 & 14.77 \\
Definitive repair at older age & 0.031 & 2.24 & 1.08 & 4.65 \\
$\mathrm{CP} / \mathrm{PR}$ prophylaxis & 0.142 & 0.62 & 0.32 & 1.18 \\
$\mathrm{~S}_{\mathrm{v}} \mathrm{O}_{2}$ monitoring & 0.002 & 0.43 & 0.25 & 0.73 \\
\hline
\end{tabular}

$C$ statistics $0.78 ; \chi^{2}$ for covariates 117.82 with 4 degrees of freedom $(p=0.0001)$. $P H$, Pulmonaty hypertension; $C P$, chlorpromazine; $P R$, prazosin.

pulmonary hypertensive events has declined significantly, from $31 \%$ (1980 to 1984$)$ to $6.8 \%$ (1990 to 1994, $p<0.001$; Table III). Moreover, the mortality rate associated with pulmonary hypertensive events among patients in whom pulmonary hypertension developed has declined significantly (71\% 1980 to 1984 to $29 \% 1990$ to 1994$)$.

By multivariable logistic regression, preoperative pulmonary hypertension was found to be the most significant predictor of postoperative pulmonary hypertensive events (Table IV). Previous pulmonary artery banding did not have a significant negative impact on the development of postoperative pulmonary hypertensive events. Absence of $\mathrm{S}_{\mathrm{V}}{ }_{2}$ monitoring and absence of prophylactic $\alpha$-blockers were additional independent risk factors for the development of subsequent pulmonary hypertensive events. Furthermore, preoperative pulmonary hypertension and absence of prophylactic $\alpha$-blockade were also independent risk factors for death associated with pulmonary hypertension. Although monitoring of pulmonary arterial pressure was associated with an increased risk of postoperative pulmonary hypertensive events, this may simply be a reflection of the fact that patients with preoperative pulmonary hypertension are most likely to have pulmonary arterial pressures monitored.

Pulmonary artery vasodilator therapy with $\alpha$-blockers is nonselective and could produce systemic hypotension, leading to an increase in morbidity. ${ }^{14}$ We have not seen a significant mortality rate associated with our treatment regimen, however, which includes starting chlorpromazine, prazosin, or both at minimal dosage $(0.25 \mathrm{mg})$ and adjusting up to $2 \mathrm{mg}$ of each. Mild systemic hypotension $(<5 \%)$ did occur in some patients, but this was only observed with the first or second dose, and volume supplements were adequate treatment in most cases. Because nitric oxide is a selective pulmonary vasodilator in neonates and infants, we plan to initiate a randomized trial of inhaled nitric oxide versus conventional prophylaxis with $\alpha$-blockers and nitrovasodilators as the first-line treatment for postoperative pulmonary hypertension.

The impact of the timing of definitive repair on morbidity and mortality related to pulmonary hypertensive events was specifically addressed in this study (Table VI). Delayed definitive repair in patients with a left-to-right shunt (atrioventricular canal, truncus arteriosus, ventricular septal defect) or patients with ductus-dependent circulation (transposition of great arteries, hypoplastic left heart syndrome) resulted in a higher incidence of pulmonary hypertensive events than seen with definitive early repair $(p=0.006$ by Fisher's Exact Test). These results are consistent with other large 
retrospective series and support the concept of early definitive repair, before irreversible pulmonary vascular remodeling occurs. ${ }^{1-6}$ In contrast, among patients with total anomalous pulmonary venous connection, neonates had a higher incidence of pulmonary hypertension than did patients older than 30 days $(p=0.052$ by Fisher's Exact Test). This difference probably reflects the fact that patients with poor preoperative conditions associated with severe pulmonary venous obstruction require emergency operation as neonates, ${ }^{15,16}$ and these patients are more likely to have postoperative pulmonary hypertensive events. Patients at high risk with total anomalous pulmonary venous connection also require neonatal repair. The recent excellent results of neonatal repair for this anomaly support this interpretation. ${ }^{3}, 17,19$

Although the mechanism of development of pulmonary hypertension remains unclear, recent studies have indicated that vasoactive mediators, including endothelin-1, may play an important role. ${ }^{20,21}$ Interestingly, McGowan and associates ${ }^{21}$ found that plasma concentrations of endothelin-1 are significantly higher in neonates with transposition of the great arteries than in patients with atrial septal defects, both before and after cardiopulmonary bypass. These findings may explain in part why patients with transposition may be more vulnerable to postoperative pulmonary hypertension than those with atrial septal defects. The relative roles in different cardiac anomalies of endothelin-1 and other vasoactive mediators, as well as the roles of endogenous and exogenous nitric oxide, require further study to elucidate the exact mechanism of postoperative pulmonary hypertensive events.

This retrospective study, which was based on a 15-year single-institution experience, has certain limitations. First, although the mechanism, incidence, and risk factors may be different for pulmonary hypertensive crisis and persistent pulmonary hypertension, it was impossible to clearly differentiate between these two complications because of the limits of retrospective review. Second, rare diseases (fewer than 10 cases in our series) such as aortopulmonary window, anomalous left coronary arteries, congenital mitral disease, and congenital pulmonary vein stenosis without total anomalous pulmonary venous return were excluded to reduce the risk of the type II error in statistical analysis, but these diseases may still represent high-risk categories for postoperative pulmonary hypertension. ${ }^{15}$ Third, other factors such as hypothermia, restless- ness, and tracheal suctioning are believed to trigger pulmonary hypertensive events, ${ }^{22}$ but these possible risk factors could not be incorporated into this analysis as a result of inconsistencies in the data.

In summary, patients with atrioventricular canal, truncus arteriosus, transposition of the great arteries, hypoplastic left heart syndrome, ventricular septal defect, and total anomalous pulmonary venous connection are at high risk for the development of postoperative pulmonary hypertensive events. Multivariable logistic regression analysis revealed that preoperative pulmonary hypertension, absence of $\mathrm{SṽO}_{2}$ monitoring, absence of prophylaxis with $\alpha$-blockers (chlorpromazine or prazosin), and definitive repair at an older age are significant risk factors for the development of postoperative pulmonary hypertension and for early death related to this complication. We conclude that monitoring of $\mathrm{S}_{\bar{v}}{ }_{2}$ and prophylactic $\alpha$-blockade significantly reduce the incidence of pulmonary hypertensive events after operation for congenital heart disease. Definitive early repair reduces the postoperative morbidity and mortality from pulmonary hypertensive events. Further clinical trials of inhaled nitric oxide and studies to elucidate the mechanism of pulmonary hypertension are necessary if we are to completely understand and eliminate this severe complication.

\section{REFERENCES}

1. Hanley FL, Heinmann MK, Jonas RA, et al. Repair of truncus arteriosus in the neonate. J Thorac Cardiovasc Surg 1993; 105:1047-56.

2. Wernovsky G, Mayer JE, Jonas RA, et al. Factors influencing early and late outcome of the arterial switch operation for transposition of the great arteries. J Thorac Cardiovasc Surg 1995;109:289-302.

3. Lupinetti FM, Kulik TJ, Beekman RH, Crowley DC, Bove EL. Correction of total anomalous pulmonary venous connection in infancy. J Thorac Cardiovasc Surg 1993;106:880-5.

4. Iannettoni MD, Bove EL, Mosca RS, et al. Improving results with first-stage palliation for hypoplastic left heart syndrome. J Thorac Cardiovasc Surg 1994;107:934-40.

5. Fukushima N, Gundry SR, Razzouk AJ, Bailey LL. Risk factors for graft failure associated with pulmonary hypertension after pediatric heart transplantation. J Thorac Cardiovasc Surg 1994;107:985-9.

6. Bando K, Turrentine MW, Sun K, et al. Surgical management of complete atrioventricular septal defects: a twentyyear experience. J Thorac Cardiovasc Surg 1995;110:1543-54.

7. Harrell FE, Lee KL, Mark DB. Tutorial in biostatistics: multivariable prognostic models-issues in developing models, evaluating assumptions and adequacy, and measuring and reducing errors. Stat Med 1996;15:361-87.

8. van Houwelingen JC, le Cessie S. Predictive value of statistical models. Stat Med 1990;8:1303-25.

9. Hanley FL, Fenton KN, Jonas RA, et al. Surgical repair of 
complete atrioventricular canal defects in infancy: twentyyear trends. J Thorac Cardiovasc Surg 1993;106:387-97.

10. Bando K, Turrentine MW, Sun K, et al. Surgical management of hypoplastic left heart syndrome. Ann Thorac Surg 1996;62:70-7.

11. Kirklin JW, Barratt-Boyes BG. Postoperative care. In: Kirklin JW, Barratt-Boyes BG, editors. Cardiac surgery. 2nd ed. New York (NY): Churchill Livingstone, 1993:214-5.

12. Nihill MR. Clinical management of patients with pulmonary hypertension. In: Adams FH, Emmanouilides GC, Riemenschneider TA, editors. Heart disease in infants, children and adolescents. 5th ed. Baltimore (MD): Williams \& Wilkins, 1994:1702-3.

13. del Nido PJ, Williams WG, Villamater J, et al. Changes in pericardial surface pressure during pulmonary hypertensive crises after cardiac surgery. Circulation 1987;76:93-6.

14. Hopkins RA, Bull C, Haworth SG, de Leval MR, Stark J. Pulmonary hypertensive crises following surgery for congenital heart defects in young children. Eur J Cardiothorac Surg 1991;5:628-34.

15. Martin LD, Wetzel RC. Regulation of pulmonary vascular tone and blood flow. In: Nichols DG, Cameron DE, Greeney WJ, Lappe DG, Ungerleider RM, Wetzel RC, editors. Clinical heart disease in infants and children. St Louis: MosbyYear Book, 1995:75-122.

16. Jones $\mathrm{O}$, Shore D, Rigby M, et al. The use of tolazoline hydrochloride as a pulmonary vasodilator in potentially fatal episode as a pulmonary vasoconstriction after cardiac surgery in children. Circulation 1981;64:134-9.

17. Raisher BD, Grant JW, Martin TC, Strauss AW, Spray TL. Complete repair of total anomalous pulmonary venous connection in infancy. J Thorac Cardiovasc Surg 1992;104:443-8.

18. Bando K, Turrentine MW, Sun K, et al. Surgical management of total anomalous pulmonary venous connection: thirty year trends. Circulation. In press.

19. Sano S, Brawn WJ, Mee RB. Total anomalous pulmonary venous drainage. J Thorac Cardiovasc Surg 1989;97:886-92.

20. Komai H, Adatia IT, Elliot MJ, de Leval MR, Haworth SG. Increased plasma levels of endothelin-1 after cardiopulmonary bypass in patients with pulmonary hypertension and congenital heart disease. J Thorac Cardiovasc Surg 1993;106: 473-8.

21. McGowan FX, Davis PJ, Siewers RD, del Nido PJ. Coronary vasoconstriction mediated by endothelin-1 in neonates: reversal by nitroglycerin. J Thorac Cardiovasc Surg 1995;109: 88-98.

22. Sumner E, Stark J. Postoperative care. In: Stark J, de Leval M, editors. Surgery for congenital heart defects. 2nd ed. Philadelphia: WA Saunders, 1994:193-233.

\section{Discussion}

Dr. Pedro del Nido (Boston, Mass.). I commend you for a thorough retrospective review of this important clinical problem. I would like to make some comments on some issues that you brought up, which I believe are very important, and also ask some questions.

First, I think we would concur with your conclusions that in the case of children with large, symptomatic left-to-right shunts, delaying corrective procedures in an effort to "allow the child to grow or decrease the risk of surgery" may in fact increase the risk of operative repair, primarily from complications related to pulmonary hyper- tension. At Boston Children's Hospital, we continue to advocate a policy of early repair for all patients with large left-to-right shunts that are unlikely to spontaneously resolve.

Second, when discussing pulmonary hypertension in children, it is important to differentiate between high pulmonary vascular resistance and pulmonary reactivity. The first is usually seen in children with long-standing left-to-right shunts or pulmonary venous hypertension. The second, however, can also be seen in neonates within the first 24 hours after cardiopulmonary bypass. The latter we usually treat with sedation and occasionally with muscle relaxants and by minimizing noxious stimuli such as suctioning.

The former problem, however, increased pulmonary vascular resistance, is more serious. It is usually treated in our institution with moderate hyperventilation. In cases where low cardiac output is seen, we would use inhaled nitric oxide as a locally active specific pulmonary antihypertensive.

In an analysis of the first 225 children who were treated at Children's Hospital with nitric oxide as an agent to decrease their pulmonary resistance, about a third of the patients were neonates. However, this spans the gamut of all ages and all diagnoses.

What we found is that in fact there are certain categories that respond much better. As you would expect, patients with Eisenmenger's disease have very little response; however, patients with pulmonary venous hypertension, that is total anomalous pulmonary venous return, mitral valve disease, or elevated left atrial pressures from cardiomyopathy, responded quite well and were in fact the best group.

My questions to you are several. First, can you differentiate for us whether your technique of using $\alpha$-blockers is effective for treating pulmonary hypertension, that is, increased pulmonary vascular resistance alone, or is it also effective in preventing the pulmonary hypertensive crises that you describe?

Second, there are inherent limitations in a retrospective review such as this one; however, was there a concurrent shift toward younger corrections in this patient population, and was that shift also at a similar time frame as when you initiated your $\alpha$-blocker program? In other words, can you differentiate for us whether these two were independent variables?

Third, you included in your analysis children with transposition of the great arteries, a group in whom repair is delayed unless they have a large ventricular septal defect and that is usually not considered at risk for pulmonary hypertension. Can you tell us what your rationale was for including these patients? Have you analyzed your data excluding this group to see whether the results are the same?

Finally, the groups that you identified as being at highest risk for postoperative pulmonary hypertension were those with atrioventricular canal, truncus arteriosus, and ventricular septal defect. On the basis of your analy sis, can you speculate for us regarding how much impact earlier repair would have had on preventing pulmonary hypertension, versus the strategy of using complex phar- 
macologic manipulations to treat children after a late repair?

Dr. Bando. Your first question is whether $\alpha$-blocker prophylaxis is effective for both persistent pulmonary hypertension and pulmonary hypertensive crisis or effective for only one of them. Because this is retrospective analysis based on our 15-year experience, it is difficult to differentiate these two categories. Our treatment strategy is pretty much the same for persistent pulmonary hypertension and pulmonary hypertensive crisis. Moderate hyperventilation with a high inspired oxygen fraction, sedation, and paralysis have been used consistently for prevention of these complications for the last 15 years. Since 1990, $\alpha$-blockers have been used in addition to prevent both of these complications. It is thus quite difficult to know the impact of $\alpha$-blockers in each of these two categories.

Related to your question, I also would like to tell you one thing that I was not able to incorporate in this study. When pulmonary arterial pressure normalized immediately after operation, these patients were more likely to have pulmonary hypertensive events, presumably a pulmonary hypertensive crisis. I believe that we are properly treating persistent pulmonary hypertension, but it may be that we are undertreating some patients at risk for pulmonary hypertensive crises.

Your second question whether early definitive repair and $\alpha$-blocker prophylaxis can be differentiated as independent risk factors. The answer is yes. By multivariable logistic regression analysis, these two indexes came out as independent risk factors.

Your third question is why we included transposition of the great arteries and intact ventricular septum. Actually, among 97 patients with transposition of the great arteries, 70 patients had intact ventricular septum and 27 had ventricular septal defects. Surprisingly, both groups had a relatively high incidence $(75 \%)$ of pulmonary hypertensive events $(8 / 70$ [11\%] for transposition of the great arteries with intact ventricular septum and 6/27 [22\%] for transposition of the great arteries with ventricular septal defect). Currently, we are analyzing risk factors for pulmonary hypertensive events in each diagnostic group, and this further analysis may tell us the risk factors within each diagnostic group.

Your last question is related to the relative impacts of early repair and $\alpha$-blocker prophylaxis on the development of postoperative pulmonary hypertensive events. Because the majority of high-risk patients after $1990 \mathrm{had}$ prophylaxis, it is difficult to stratify the patients on the basis of the timing of the operation. I can say, however, that early definitive repair is probably the best measure for the prevention of pulmonary hypertensive events.

Dr. Richard A. Hopkins (Washington, D.C.). I concur with the praise for this study in terms of the volume and the amount of work it represents. We did a similar study in 1984 and 1985, when I was at Great Ormond Street, when the pediatric size oximetric catheter first became available, and many of our findings were exactly as you have found, with a couple of differences. We had the additional advantage of having a frequency modulated (FM)-type record so that we could, in fact, relate nursing events to the crises.

We found at that time that patients with atrioventricu- lar canals were a particularly high-risk group, unlike yours. Of course, at that time the fashion was to operate on these children at around 1 year of age. Subsequent to that experience, I have been operating on them at between 3 and 5 months of age. Although we see hyperreactivity, the crisis events with falling systemic output have virtually disappeared. I wonder whether you have seen that same change with time as you have decreased age at operation.

Second, in that article that we published in our sister organization's journal, the European Journal of Cardiothoracic Surgery, we defined pulmonary hypertensive crisis not as a rise above $50 \%$ of systemic pressure but as a rise to or exceeding systemic pressure, partly because so many of these children already have pulmonary artery pressures that ride around the $50 \%$ to $60 \%$ level anyway. That has a practical feature as well. If in fact the critical component is the fall in the systemic output and not the pulmonary artery pressure per se, you limit overdiagnosis of this entity. One of the problems in a pediatric intensive care unit is that the staff can become very frightened about hyperreactivity of the pulmonary artery pressure, and you can end up with patients being kept on hyperventilation for a prolonged period when what you are dealing with is hyperreactivity rather than true crises. Have you found the lower pressure definition to be problematic when attempting to wean these children from suppressive therapy?

Dr. Bando. As indicated in my presentation, the incidence of pulmonary hypertensive events in patients with atrioventricular canal was less than we expected, presumably because all these patients had $\alpha$-blocker prophylaxis and, more recently, underwent repair before the age of 6 months. I also stress that once pulmonary hypertensive events occurred in patients with atrioventricular canal, the mortality rate was high $(6 / 11,54.5 \%)$. Regarding the definition of postoperative pulmonary hypertensive crisis versus ongoing pulmonary hypertension on the basis of a retrospective chart review, a prospective study is certainly important to identify the risk factors for pulmonary hypertensive events. I believe, however, that it is still difficult to predict whether hyperreactivity will progress to "true" pulmonary hypertensive crisis.

\section{Appendix: Potential risk factors for the development of pulmonary hypertension, overall operative mortality, and mortality related to pulmonary hypertension}

A. Preoperative risk factors

1. Age at repair

2. Sex

3. Year of operation

4. Weight at repair

5. Prematurity

6. Other cardiac lesions

7. Other noncardiac problems

8. Previous palliation (pulmonary artery banding, other palliations)

9. Preoperative pulmonary hypertension

B. Intraoperative risk factors

1. Total cardiopulmonary bypass

2. Circulatory arrest time

3. Aortic crossclamp time 
4. Inotropic support (dopamine, dobutamine, epinephrine; graded)

5. Nitroglycerin or nitroprusside; graded

6. Intraoperative transesophageal echocardiography

C. Postoperative risk factors

1. Monitoring

a. Pulmonary arterial pressure

b. Pulmonary arterial saturation

c. Right atrial pressure

d. $\mathrm{Sv}_{2}$

e. Systemic pressure

f. Arterial blood gas values (oxygen tension, carbon dioxide tension, $\mathrm{pH}$ )

2. Management a. Inotropic support (dopamine, dobutamine, epinephrine; graded)

b. Nitroglycerin or nitroprusside; graded

c. Prophylaxis with chlorpromazine or prazosin

d. Delayed sternal closure

3. Results

a. Pulmonary hypertensive events (pulmonary hypertensive crisis or persistent pulmonary hypertension)

b. Hospital mortality

c. Hospital mortality associated with pulmonary hypertensive events

d. Late mortality

e. Current New York Heart Association functional class 